\title{
A Comparative Study of Mathematics Assessment Practices between Malaysian and South Korean Secondary Schools Mathematics Teachers
}

\author{
Abdul Halim Abdullah, ${ }^{1, *}$, Bomi Shin², Muhammad Sani Abdurrahman ${ }^{3}$ \\ ${ }^{1}$ School of Education, Faculty of Social Sciences and Humanities, Universiti Teknologi Malaysia (UTM), Malaysia \\ ${ }^{2}$ College of Education, Chonnam National University, South Korea \\ ${ }^{3}$ Department of Mathematics, Waziri Umaru Federal Polytechnic, Nigeria
}

Received May 20, 2020; Revised June 23, 2020; Accepted July 20, 2020

\section{Cite This Paper in the following Citation Styles}

(a): [1] Abdul Halim Abdullah, Bomi Shin, Muhammad Sani Abdurrahman, "A Comparative Study of Mathematics Assessment Practices Between Malaysian and South Korean Secondary Schools Mathematics Teachers," Universal Journal of Educational Research, Vol. 8, No. 11, pp. 5015-5035, 2020. DOI: 10.13189/ujer.2020.081102.

(b): Abdul Halim Abdullah, Bomi Shin, Muhammad Sani Abdurrahman (2020). A Comparative Study of Mathematics Assessment Practices Between Malaysian and South Korean Secondary Schools Mathematics Teachers. Universal Journal of Educational Research, 8(11), 5015-5035. DOI: 10.13189/ujer.2020.081102.

Copyright $\bigcirc 2020$ by authors, all rights reserved. Authors agree that this article remains permanently open access under the terms of the Creative Commons Attribution License 4.0 International License

\begin{abstract}
This study compares the assessment practices of Malaysian and South Korean lower secondary school mathematics teachers to help explain the differences that have been found consistently between the achievement levels of Malaysian and Korean students in the TIMSS and PISA. A set of questionnaires was developed and used. It consists of item in three constructs, namely, formative, summative and diagnostic assessment. Cronbach's alpha coefficient for the total score of the questionnaire was 0.94 . A total of 71 Malaysian respondents and 51 South Korean respondents were involved in the study. To gather richer data, the interview was done in a manner which could explain the results. A total of three lower secondary school mathematics teachers from each country participated in the interview. The findings show that mathematics teachers in both countries use open-ended and subjective questions versus multiple choice questions in implementing formative assessment. The mathematics teachers of both countries also understand the importance and purpose of implementing formative assessment in mathematics classes. Both education systems are highly oriented to examinations, but do not emphasise TIMSS and PISA assessments. In Malaysia, not all schools are chosen to be involved in those assessments. While the attitude of the students towards any tests or examinations makes South Korean students always ready to face the two assessments. Besides that, one of the aspects that Malaysia's education
\end{abstract}

system can learn is the implementation of diagnostic assessments that is highly emphasised and systematically implemented in South Korea's education system.

Keywords Mathematics Assessment, Malaysia, South Korea, Formative, Summative, Diagnostic

\section{Introduction}

South Korea, a country located in the same Asian continent, serves as an excellent benchmark for Malaysia to conduct further studies for educational development. Comparisons between both countries are noteworthy. Malaysia is a Southeast Asian country occupying a total area of $330,803 \mathrm{~km}^{2}$ which includes a federation of 13 states and three different federal territories. The current population of Malaysia is about 32 million people. Unlike other countries, Malaysia is a multiracial country with varied ethnic groups living in the country. The three existing major ethnic groups are Malay, Chinese and Indian. This multicultural background makes Malaysia a unique country with diverse religions, foods, cultures and customs. In contrast, South Korea is an East Asian country occupying a total area of $100,210 \mathrm{~km}^{2}$ in the 
southern part of the Korean Peninsula and on the east of the Asian mainland. South Korea is a republican country, which is why it is known as the Republic of Korea. Provinces would refer to first-level administrative divisions and there are nine provinces within South Korea. The current population of South Korea is 51 million people. The country is predominantly occupied by a homogenous society of Korean people, with the official language and script being Korean and Hangul respectively.

The economic and political relations between South Korea and the Association of Southeast Asian Nations (ASEAN), including Malaysia, has progressively grown over time [1]. In terms of trade, Malaysia is ranked as South Korea's $12^{\text {th }}$ largest business partner [2], where Malaysia continues to collaborate in various areas such as information and communication technology (ICT) and 5G, oil and gas, green technology and urban development [3]. Based on 2016 statistics in the tourism industry, Malaysia was ranked 7th in terms of number of visitors to South Korea as tourists. In 2017, South Korea was named as one of the top 10 source markets for Malaysia's tourism sector. This cooperation is set to continue under the leadership of the sixth Prime Minister of Malaysia, Tun Mahathir Mohamad who had introduced the Look-To-The-East Policy on the 8th February 1982. The policy is aimed at enhancing the management and development performance in Malaysia by creating a community of Malaysians with positive values and work ethics, who would contribute in the country's development, and follow the examples demonstrated by Japan and South Korea.

In particular, there is a very large gap in the area of mathematical achievements under the same international assessments between both countries. The recently conducted Programme for International Student Assessment (PISA) and The Trends in International Mathematics and Science Study (TIMSS) assessments shows that the mathematics performance of Malaysian students was not on par with the world standards. The results indicated that the Malaysian education system is not producing the expected academic outcomes in terms of teaching and learning of mathematics. In contrast, the results were different for South Korea. PISA and TIMSS assessments show that the mathematics results of Malaysia and South Korea are at the opposite ends of the continuum. South Korea has been an exemplar of excellent track record in Mathematics in all of the studies to other countries, leaving most of the world education system still in awe of its achievements. The outstanding performance by South Korea indicates that its education system has been effective and successful in developing students academically to be able to achieve world class standards.

The graph in Figure 1 shows that Malaysia faired dismally in TIMSS assessments. TIMSS has four types of International benchmarks for mathematics achievements. The benchmark types and respective values as indicated in brackets are: Advanced International Benchmark (625), High International Benchmark (550), Intermediate International Benchmark (475) and Low International Benchmark (400). Figure 1 shows the comparison of TIMSS Mathematics achievements for the $8^{\text {th }}$ grade students between Malaysia and South Korea. In TIMSS assessment for year 1999, South Korea had achieved 604 in scores, which had exceeded the High International Benchmark. On the other hand, Malaysia had only obtained 519 in scores, and had exceeded the Intermediate International Benchmark only. The TIMSS assessments for the years 2003, 2007 and 2011 indicated that South Korea has continued to show improvements and maintained its position in the High International Benchmark. However, Malaysia had shown a decline in its performances from year 2003 to year 2011. Despite a slight decrease in South Korea's performance as indicated in TIMSS assessment for year 2015, it had still surpassed the high international benchmark. Malaysia had only managed to show a slight increase in TIMSS assessment for year 2015. TIMSS assessment is based on a framework developed from collaboration with participating countries. It is organised into two dimensions, namely (1) Content Domain, which refers to the mathematics subjects to be evaluated, and (2) Cognitive Domain, which focuses on the thinking processes, that are to be expected from students as they engage in the mathematical content. Based on Table 1, it can be seen that the $8^{\text {th }}$ grade South Korean students had outperformed the Malaysian $8^{\text {th }}$ grade students in all content domains, namely Number, Algebra, Geometry, Data and Chance; and also, in all cognitive domains, namely Knowing, Applying and Reasoning, from TIMSS 1999 until TIMSS 2015 assessment periods.

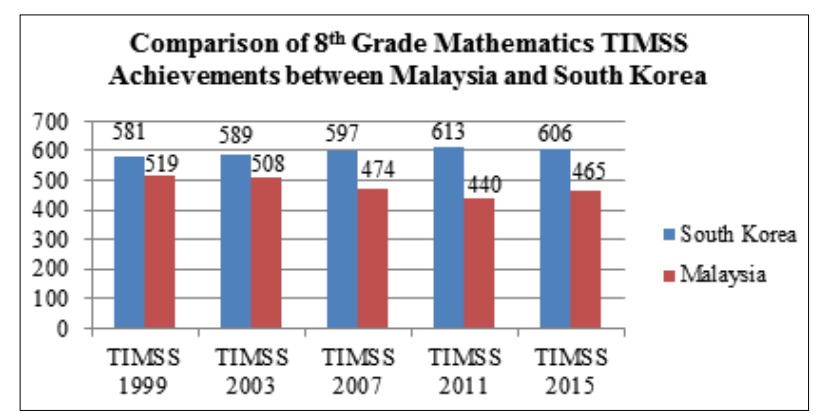

Figure 1. The Malaysian and South Korean $8^{\text {th }}$ grade mathematics TIMSS achievements 
Table 1. A comparison between content and cognitive dimension

\begin{tabular}{|c|c|c|c|c|c|c|c|c|}
\hline TIMSS & \multicolumn{5}{|c|}{ Content Dimension } & \multicolumn{4}{c|}{ Cognitive Dimension } \\
\hline Malaysia & Number & Measurement & Data & Geometry & Algebra & Knowing & Applying & Reasoning \\
\hline 1999 & 532 & 514 & 491 & 497 & 505 & - & - & - \\
\hline 2003 & 524 & 504 & 505 & 495 & 495 & 506 & 512 & 503 \\
\hline 2007 & 494 & - & 459 & 474 & 455 & 473 & 477 & 466 \\
\hline 2011 & 451 & - & 429 & 432 & 430 & 444 & 439 & 426 \\
\hline 2015 & 472 & - & 451 & 455 & 467 & 472 & 463 & 453 \\
\hline South Korea & Number & Measurement & Data & Geometry & Algebra & Knowing & Applying & Reasoning \\
\hline 1999 & 570 & 571 & 576 & 573 & 585 & - & - & - \\
\hline 2003 & 586 & 577 & 569 & 598 & 597 & 592 & 584 & 582 \\
\hline 2007 & 592 & - & 602 & 600 & 608 & 608 & 600 & 592 \\
\hline 2011 & 618 & - & 616 & 612 & 617 & 616 & 617 & 612 \\
\hline 2015 & 601 & - & 600 & 612 & 612 & 607 & 606 & 608 \\
\hline
\end{tabular}

Based on the analysis above, it is clear that the mathematical skills of South Korean students had greatly outweighed that of Malaysian students. Therefore, it is important for Malaysian researchers to study why Malaysian students did not perform well in TIMSS and PISA assessments, in a manner similar to the South Korean students. Hence, Malaysian researchers should investigate the strategies or processes adopted by countries which will contribute to students performing well in the tests, and as to how the students can achieve the outstanding results. Therefore, this study will compare the Malaysian and South Korean education system in terms of their mathematics curriculum, pedagogy and assessment. Previous studies have shown that the success of a country's education system depends on the design of its curriculum, pedagogy and assessment. According to [4], an appropriate curriculum, pedagogy and assessment will support the students' learning abilities, especially in the context of mathematics.

\section{The Need to Study the Comparisons in Assessment between Malaysia and South Korea}

Through the experience of having meaningful curriculum, quality teaching, and assessment, students will become active and perform well in a classroom [5]. The curriculum, pedagogy and assessment components seem to be interconnected with each other $[6,7]$. However, these three major components are said to be independent of each other $[8,9]$. Many previous studies have shown the positive effects of these three components on students' academic achievements. Ref [10] explained how the standards and content of curriculum, form and content of assessment and classroom teaching are among the factors that contribute to the gap in students' mathematics achievement.

In the assessment component, each country has its own assessment processes in mathematics education. Assessment is implemented to measure whether content and learning standards have been achieved. Results from assessments help students to identify the gap between current achievements and learning standards in the current curriculum [11]. In addition, an assessment is important since it is part of the process in improving the education system [12]. Assessment is also an important component taken into consideration in the design and delivery of the curriculum [12]. Ref [13] has listed five general goals of mathematical assessment. They are: (1) to refine the teaching and learning process, (2) to evaluate the student's progress, (3) to provide feedback for the student to reflect, (4) to share expectations, and (5) to improve attitudes toward mathematics. The results from studies conducted by $[14,15]$ show that the practice of assessing students has a very significant effect on students' achievement. Each country, however, have outlined their very own mathematical assessment and evaluation policy in achieving their own desired goals. Many studies when reviewed have suggested that the mathematical assessment varied from country to country. In the case of education in United Kingdom, formative assessment plays an important role that supports the newly revised curriculum [16-18] show that formative assessments have a positive impact on the students' academic achievement. For diagnostic purposes, United Kingdom has introduced a computer-based assessment (CBA) in the year 2012, which involves literacy and numeracy assessment [16]. From summative assessment, New Zealand has moved towards a broad focus on formative assessment [19].

Likewise, Denmark has taken steps in integrating formative assessment in their education system by establishing an evaluation portal. This portal provides guidance to teachers on how to integrate various approaches of formative assessment into daily teaching and provide ways to exploit the data from the diagnostic CBA to plan the lessons [16]. Australia is emphasising on using this assessment for the learning process, where teachers are given the opportunity to decide how and when to assess a student's achievement, as they plan for the work students will do. This is possible by using a range of appropriate assessment strategies, including self-assessment and peer assessment [20]. Many countries have increasingly develop more comprehensive 
evaluations and frameworks which involves more variety of assessment strategies. However, examinations still remain a key assessment strategy across countries [21]. In the Western and European countries, the assessment strategies are shifting towards classroom based assessment (formative), although some challenges exist towards the goals. In the eastern countries, examinations have still remained as an important part of the assessment cultures, especially in many Asian countries. Parents in South Korea are willing to spend extra money to send their children to tuition classes to ensure that their children excel in the examinations [22]. On the other hand, Malaysia's emphasis is on public examination results as an important factor in the advancement of students into higher education or for better job opportunities [23]. In that regard, as both Malaysia and South Korea are Asian countries, examinations are still being emphasised. This study will reveal other factors in the assessment aspect that have led to a large mathematical achievement gap between Malaysian and South Korean students.

\section{Research Methodology}

Assessing different educational systems of different countries is a discipline in the social sciences field. It aims to examine the sources, methods of working, and results of the education system, as well as major education issues, from a comprehensive perspective, diversity of disciplines as well as across countries and cultures [24]. Assessing different educational systems involves the analysis of the education system and the problem of two or more aspects of social, political, economic, cultural, ideological and other contexts [25]. In this regard, this study is a comparison study of education using case study design. Case study refers to a form of study in a closed system to identify the meaning and understanding of a situation or subject [26]. In case studies, the researcher is considered as the main instrument in the process of collecting and analyzing data. This study looks at the lower secondary mathematics education system in Malaysia and South Korea separately, and then explores similarities and differences and compares current practices in both systems for future policy formulation. The comparison conducted in this study is not meant to deem one system better than the other, but more to understand the factors that underlie the similarities and differences, as well as current practices in lower secondary mathematics education so that both countries can learn from one another. The goal of studying the education system of other countries is to know what can be learned and improved and will further contribute to better policies and practices in their respective countries [27]. Through comparison, this study can produce "intensive explanations and interpretations" [26] of the differences in students Mathematics achievement in both countries and, thereby providing implications for mathematics education. This study is generally aimed at comparing the mathematics curriculum, pedagogy and assessment at lower secondary school level between Malaysia and South Korea. To achieve that, various types of educational data were collected. To compare the lower secondary school mathematics curriculum in both countries, the empirical information from journal articles, government policy documents, and mathematics textbooks were collected. The literature review of related empirical and conceptual research paper was also conducted. To study the components of pedagogy and assessment of lower secondary school mathematics in both countries, the quantitative method using a set of questionnaire was used. Items are scored on a scale of $(1)=$ Never, $(2)=$ Seldom, (3) = Sometimes, (4) = Often, and (5) = Always. Questionnaire used in this study is divided into two main sections, namely Section A, which contains seven items relating to the respondents' demographic information; Section B which consists of eight constructs, according to the [28] framework with their number of items and Cronbach's alpha coefficient as shown in the following Table 2: Constructs of the Questionnaire. According to the interpretation by [29], all constructs were found to be highly reliable. Items from the questionnaire were analyzed using descriptive statistics, which refers to frequency and percentage values.

Table 2. Constructs of the questionnaire

\begin{tabular}{|l|c|c|}
\hline Construct & $\begin{array}{c}\text { Number of } \\
\text { items }\end{array}$ & $\begin{array}{c}\text { Cronbach's } \\
\text { Alpha }(\alpha)\end{array}$ \\
\hline Assessing students through: & 12 & 0.91 \\
(i) Formative Assessment & 16 & 0.90 \\
(ii) Summative Assessment & 11 & 0.95 \\
(iii) Diagnostic Assessment & 39 & 0.94 \\
\hline Total & \multicolumn{2}{|}{} \\
\hline
\end{tabular}

In qualitative research, participants' thoughts, ideas and perceptions can be gathered in many ways. Among the methods include observation, document analysis, interviews, and reflections from participants. The method mostly used by researchers is interview. The purpose of an interview is to describe an individual's experience "as it is lived, felt, undergone, made sense of and accomplished by human beings" [30]. According to [31], interviews differ from other research approaches as they bring together researchers with participants in direct conversations that may reflect authentic experiences. For the purposes of gathering richer data, the interview was done in a manner that could additionally explain the results obtained. A total of three lower secondary school mathematics teachers from both countries were involved in the interviews. The interviews were conducted in a structured manner, and according to the required interview protocol which lasted for 30 minutes. After the interview fieldwork was done, all of the collated data was transcribed, codified and compared. 
The respondents' demographic profiles are shown in Table 3. As can be observed, 71 Malaysian lower secondary school mathematics teachers and 51 South Korean middle school mathematics teachers were involved in this study. Most of the Malaysian respondents were females, half of whom were between the ages of 30 to 39. All of the teachers held at least a Bachelor's degree. In terms of teaching experience, $28.2 \%$ of the respondents had 11 to 15 years of experience, while $29.6 \%$ of them had 5 to 10 years of teaching experience. Only $8.5 \%$ of the respondents had more than 20 years of experience as teachers. Most of them (74.6\%) worked in schools located in urban areas. Similarly, the majority of the South Korean respondents were also female teachers. Their ages were between $30-39$ years $(43.1 \%)$ and $40-50$ years (39.2\%). Their schools were all located in urban areas. All of them had at least a Bachelor's degree.

Table 3. Demographic characteristics

\begin{tabular}{|c|c|c|c|c|}
\hline \multirow{2}{*}{ Characteristic } & \multicolumn{2}{|c|}{ Malaysia } & \multicolumn{2}{|c|}{ South Korea } \\
\hline & $\mathrm{n}$ & $\%$ & $\mathrm{n}$ & $\%$ \\
\hline \multicolumn{5}{|l|}{ Gender } \\
\hline Male & 8 & 11.3 & 12 & 23.5 \\
\hline Female & 63 & 88.7 & 39 & 76.5 \\
\hline \multicolumn{5}{|l|}{ Age } \\
\hline$<30$ & 9 & 12.7 & 6 & 11.8 \\
\hline $30-39$ years & 38 & 53.5 & 22 & 43.1 \\
\hline $40-50$ year & 19 & 26.8 & 20 & 39.2 \\
\hline$>50$ years & 5 & 7.0 & 3 & 5.9 \\
\hline \multicolumn{5}{|l|}{ Academic qualification } \\
\hline Doctor of Philosophy & 1 & 1.4 & 1 & 2.0 \\
\hline Master & 8 & 11.3 & 21 & 41.2 \\
\hline Bachelor & 62 & 87.3 & 29 & 56.9 \\
\hline \multicolumn{5}{|l|}{ Period served as a teacher } \\
\hline$<5$ years & 14 & 19.7 & 12 & 23.5 \\
\hline $5-10$ years & 21 & 29.6 & 13 & 25.5 \\
\hline $11-15$ years & 20 & 28.2 & 8 & 15.7 \\
\hline $16-20$ years & 10 & 14.1 & 12 & 23.5 \\
\hline$>20$ & 6 & 8.5 & 6 & 11.8 \\
\hline \multicolumn{5}{|c|}{ Years of experience in teaching mathematics } \\
\hline$<5$ years & 21 & 29.6 & 12 & 23.5 \\
\hline $5-10$ years & 21 & 29.6 & 13 & 25.5 \\
\hline $11-15$ years & 18 & 25.4 & 8 & 15.7 \\
\hline $16-20$ years & 5 & 7.0 & 12 & 23.5 \\
\hline$>20$ years & 6 & 8.5 & 6 & 11.8 \\
\hline \multicolumn{5}{|l|}{ School location } \\
\hline Urban & 53 & 74.6 & 50 & 100 \\
\hline Rural & 18 & 25.4 & 0 & 0 \\
\hline
\end{tabular}


In the current study, three mathematics teachers from each country were interviewed. The interview lasted about 30 minutes for each session and it was conducted based on the availability of the teachers. The demographic details of the interviewees are shown in Table 4 below.

Table 4. Interviewee's information

\begin{tabular}{|c|c|c|c|c|}
\hline $\begin{array}{c}\text { Mathematics } \\
\text { Teacher }\end{array}$ & Country & $\begin{array}{c}\text { Years of } \\
\text { experience in } \\
\text { teaching } \\
\text { mathematics }\end{array}$ & Gender & Label \\
\hline 1 & Malaysia & 14 & Female & TM1 \\
\hline 2 & Malaysia & 5 & Female & TM2 \\
\hline 3 & Malaysia & 14 & Female & TM3 \\
\hline 4 & $\begin{array}{c}\text { South } \\
\text { Korea }\end{array}$ & 12 & Female & TK1 \\
\hline 5 & $\begin{array}{c}\text { South } \\
\text { Korea }\end{array}$ & 6 & Female & TK2 \\
\hline 6 & $\begin{array}{c}\text { South } \\
\text { Korea }\end{array}$ & 8 & Female & TK3 \\
\hline
\end{tabular}

\section{Findings and Discussions}

The findings and discussion are divided into three types of assessment which are formative assessment, summative assessment and diagnostic assessment. According to [32], teachers can implement a few types of assessment in the teaching and learning process based on the purpose of assessment. Formative assessment refers to formal and informal assessments used by teachers in the learning process in order to adapt teaching and learning activities and to improve students' achievements. It is an assessment which takes place continuously in the mathematics teaching and learning process. Formative assessment is conducted frequently to identify the needs of learning, provide feedback, and improve a specific learning strategy. It has been identified as one of the most effective strategies to improve students' achievements in schools.

As shown in Table 5, more than half of the Malaysian respondents chose "often" or "always" for Items 1 $(64.8 \%), 5(84.5 \%)$, and $10(78.9 \%)$. These items are related to the type of questions given to students in formative assessment. The Malaysian mathematics teachers agreed that they used open-ended questions and in a subjective form rather than multiple-choice questions. Nevertheless, [33] found that the Malaysian teachers usually ask lower cognitive questions. Although these teachers prepared open-ended questions, they expected students to provide specific answers. It was also found that most of the questions focused on the content, structure and knowledge of the students that required them to provide specific and precise answers. In other words, most of the questions are under the students' Zone of Proximal Development (ZPD) that do not help encourage their thinking skills.

Apart from that, the Malaysian education system puts a lot of emphasis on problem solving by making it one of the objectives in secondary schools' mathematics curriculum. The objective is to practice mathematics reasoning, communicate in terms of mathematics, and form a relation constantly [34]. Problem solving involving non-routine problems basically demands a higher level of thinking and reasoning. This skill needs to be cultured by teachers in order to prepare students who are capable of competing at the global level. Ref [35] found that mathematics teachers have some knowledge about non-routine mathematics problems and they are aware that non-routine problems are important in allowing students to think. However, the level of teachers' knowledge about non-routine mathematics problems is not parallel with their skills to solve and develop a non-routine mathematics problem.

For the second item in Table 5, almost more than half of the Malaysian teachers chose "never", "seldom" or "sometimes". Some of the teachers agreed that they used subjective questions rather than objective questions in mathematics classes for the purpose of formative assessment. This is a positive finding, as supported by [36] who states that subjective questions provide opportunities for students to explain their thoughts in writing. Multiple-choice questions, on the other hand, do not reflect students' knowledge about a mathematics concept [37]. For the items related to teachers' intent to implement formative assessment, which are Items 3, 7, 8, 9 and 11, most of the teachers answered "often" or "always" with $64.8 \%, 73.2 \%, 78.8 \%, 81.7 \%$ and $66.2 \%$ respectively. This finding shows that the mathematics teachers in this study understood the importance of formative assessment in mathematics classes. This quantitative finding is parallel with the interview results. Some of the excerpts given by the teachers are as follows:

"From the aspect of students' evaluation, usually many teachers are still practising formative evaluation. I mean, in every class, teachers just take randomly on how students answer a question. Sometimes, after teaching, teachers ask students to submit work-books or homework. This is what we look at. I mean, at that point, have the students mastered the lesson or not? This thing is clearer when we look at the exams. When exams come, we see the ability of the students to answer them. From there, we get the feedback regarding their ability". [TM1: H1]

"I identify students' confusion, misunderstanding, or problem they face by marking their formative evaluations immediately. For example, in the group, I display their answers and I give them the answers immediately. If the answers are wrong, I tell them why. I also ask them to explain. If I do not explain, I will ask them to explain. For example, through gallery work and $21^{\text {st }}$ century learning. I display the answers in front of the class. So, I will walk around the class to look for students' weaknesses". [TM3: H1] 
These results are in line with the practice at lower secondary schools in Malaysia; formative assessment is parallel with the learning and teaching process, while summative assessment is conducted at the end of a learning unit, a term, a semester or a year. In implementing the assessment, teachers need to construct items, administer, check, record and report students' command in the subject based on the Curriculum Standard and Assessment Document (CSAD) [34]. These qualitative findings show that the teachers understood the purpose of implementing summative assessment. Ref [38] found that formative assessment can improve students' achievements in mathematics. Meanwhile, [39] claim that formative assessment decreases anxiety and improves students' performances in mathematics.

Nevertheless, Malaysian teachers place a greater emphasis on the understanding aspect, which is the cognitive domain in formative assessment. One of the teachers agreed that she looked at students' understanding towards a mathematics concept, and other affective aspects such as attitude, motivation and others. Among the excerpts about this matter are:

"Among the variables that my evaluation from students in the mathematics class is comprehension. Motivation is also one variable, especially the low-level class. I am worried if my students are too passive. So, I create something that attracts them so that they will move actively. I give them group activities to make them more active. When they understand, they become more enthusiastic. They will ask more and more questions. We could see their motivation is increasing". [TM1: H1].

"First, I evaluate based on examination results. I could evaluate whether they are able to solve problems or not. From there, we could identify their knowledge. Sometimes, they do not memorise the multiplying table. Sometimes they are slow in understanding a certain problem. Second, we can look at group activities. Sometimes, low-level students are passive. They are only looking at their friends and not doing anything. They will not be contributing to group activities. Sometimes, I conduct formative tests for every topic, but they still could not solve that problem". [TM2: H2].

Besides the cognitive domain, the psychomotor and affective domains must also be given attention. It is in accordance with the Malaysia National Education Philosophy that aims to produce students who are well balanced in physical, emotional, spiritual and intellectual aspects. Among the mathematics learning objectives in lower secondary schools in Malaysia are to nurture good values, to be positive towards mathematics, and to develop generic skills for the $21^{\text {st }}$ century challenges [34]. With regard to the use of formative assessment in mathematics classes, $78.9 \%, 55.0 \%$ and $64.8 \%$ of the Malaysian respondents answered "often" or "always" on
Items 4, 6 and 12. This finding shows that the Malaysian teachers use various methods to assess their students in mathematics classes. Two of the interviewed teachers stated that they used presentations as one of the methods for formative assessment in mathematics classes. Excerpts of the related answers are shown below:

"We evaluate their presentations. Usually, after solving the problems, they will present in front of their friends or they will paste it on the board. Teachers will look at the solution step by step. Teachers must observe the students' solutions. We must correct the solutions that are wrong. We could notice this when we give them new questions". [TM1: H1]

"For presentations, every group will submit a paper. If students are active, they will be eager to go to the front. So, we could know whether students understand or not. If a student is passive, he or she will sit down quietly. It means that they do not understand the activities that they have in the group". [TM2: H1]

Ref [40] discuss the participatory and non-participatory techniques as part of the formative assessment methods for the achievement of learning outcomes in four different subjects. Statistics shows that students who are assessed by the participatory technique score a higher grade than those who are not assessed by this method. Ref [41] describe a few reflective practices related to formative assessment; one of them requires teachers to use various forms of assessment. Formative assessment is part of students' daily practice and continuous learning [42]. Students who do not carry out certain assignments have a chance to show their knowledge and skills to their teachers and friends. The various techniques also provide information about students' ability and performance for the direction of subsequent learning.

The mathematics teachers in South Korea also emphasise on formative assessment. As shown in Table 5, $56.9 \%, 60.8 \%, 66.6 \%$ and $76.4 \%$ of the respondents answered "often" or "always" for Items 3, 8, 9 and 11. When asked about how they assess their students in mathematics classes, some of the answers are given in the following excerpts:

"I conduct an evaluation that observes students on how they develop their ideas in a proposed task. I also conduct an oral assessment to evaluate the process of solving and explaining a problem at the end of a unit". [TK1: H1]

"I understand the students' level of knowledge through questions during the mathematics class. I observe how much they participate in the group learning. I perform a paper test to evaluate their ability to solve problems". [TK2: H1]

"It is largely divided into performance evaluation and comprehensive evaluation. In performance evaluation, it is based on presentations, attitudes, assignments, and essays. In presentations and attitudes, students are observed and evaluated for active participation in class 
activities. They are assessed for their sincere performances in the middle of a class. Narrative evaluations assess their ability to write narrative answers". [TK3: H1]

The above excerpts show that the South Korean mathematics teachers used various approaches in assessing students. In a document issued by the Ministry of Education Korea, in Part (4) which is Guidelines for Teaching and Learning, and Assessment, (B) Guidelines for Assessment and (2) Methods of Assessment, it is stated that students' mathematics learning is assessed quantitatively and qualitatively using various assessment methods such as written examination, project assessment, portfolio, observation, interview, verbal assessment, self-assessment and peer-assessment. The finding of the current study is parallel with [43] who assert that most of the mathematics teachers in South Korea are implementing formative assessment. However, only a few of them provide questions based on students' ability after implementing the first formative assessment. Based on the outcome of the first formative assessment, teachers must provide questions based on students' ability in solving either supplementary process problems or advanced process problems. This is because the $7^{\text {th }}$ curriculum is student-centred and emphasises on students' ability. According to [43], in mathematics classes, teachers use power-point slides in implementing formative assessment to save time. Ref [44] claims that some of the teachers in South Korea put a greater emphasis on formative assessment although it is only used for improvement. Ref [45] claims that, in mathematics assessment, students are given options to use technology tools such as calculator, computer, education software and various teaching tools. Interview data have shown that teachers implemented written tests and other various methods in formative assessment, a finding that is parallel to that of [46]. The following excerpts are given when the teachers were asked about the variables assessed in mathematics classes.

"I reflect students' understanding about $90 \%$ and attitude about 10\%”. [TK1: H1]

"Students' understanding and class participation". [TK2: $\mathrm{H} 1]$

"I evaluate students' understanding in a narrative evaluation, and in normal times, I evaluate class participation, good work, active interaction and presentation. I use peer assessment, self-assessment, and observation during the lessons. I mainly use observation evaluation and narrative evaluation, etc." [TK3: H1]
The above responses show that the teachers looked at both cognitive and affective domains as highlighted by [45]. According to them, the outcome of assessment in cognitive domain is highly important. The following was the excerpt given by a teacher when asked whether there was any specific instrument to assess the cognitive aspect.

"The perception of mathematics seems to be evaluated through interviews. If the concept is negative, you can discuss it. If the viewpoint is narrow, the evaluation and feedback can be carried out in a way that introduces more aspects of mathematics. Mathematical thinking seems to be assessed through observation and evaluation during class. You can check the level by observing how they solve the problem and how they explain it". [TK1: H1]

This finding shows that the South Korean mathematics teachers used various techniques to assess their students' cognitive and affective domains. Formative assessment encourages the usage of various types of assessment and emphasises on problem features in order to assess the process and output of students' thinking [47]. The Ministry of Education South Korea asserts that mathematics assessment is intended to improve student's mathematics learning, to develop students holistically, and to improve learning practice through useful information about students' cognitive and affective domains.

Besides that, $51.0 \%$ and $76.4 \%$ of the South Korean respondents answered "often" or "always" for Items 10 and 11. These items are related to the usage of subjective questions or multiple-choice questions. Most of the mathematics teachers in this study frequently used subjective questions rather than multiple-choice questions. Through written tests, students' misconception, mistakes or incomprehension towards a mathematics concept can be identified. According to [48], the emphasis on assessment has shifted from a question that needs a specific answer to a question that requires a higher level of thinking ability, which prepares a student to face the future of South Korea. This is evident with the increase of open-ended questions and essay questions that encourage the process of thinking among students. Besides that, the focus is shifted from summative assessment to formative assessment, which provides information about teaching. Meanwhile, according to [49], multiple-choice questions must be reduced; descriptive assessment, observation, interview and self-assessment are some of the methods that must be emphasised in mathematics classes. 
Table 5. Construct H: Formative assessment

\begin{tabular}{|c|c|c|c|c|c|c|c|c|c|c|c|c|c|c|c|c|c|c|c|c|c|}
\hline & \multirow{3}{*}{ Item } & \multicolumn{10}{|c|}{ Malaysia } & \multicolumn{10}{|c|}{ South Korea } \\
\hline & & \multicolumn{2}{|c|}{ Never } & \multicolumn{2}{|c|}{ Seldom } & \multicolumn{2}{|c|}{ Sometimes } & \multicolumn{2}{|c|}{ Often } & \multicolumn{2}{|c|}{ Always } & \multicolumn{2}{|c|}{ Never } & \multicolumn{2}{|c|}{ Seldom } & \multicolumn{2}{|c|}{ Sometimes } & \multicolumn{2}{|c|}{ Often } & \multicolumn{2}{|c|}{ Always } \\
\hline & & $\mathrm{n}$ & $\%$ & $\mathrm{n}$ & $\%$ & $\mathrm{n}$ & $\%$ & $\mathrm{n}$ & $\%$ & $\mathrm{n}$ & $\%$ & $\mathrm{n}$ & $\%$ & $\mathrm{n}$ & $\%$ & $\mathrm{n}$ & $\%$ & $\mathrm{n}$ & $\%$ & $\mathrm{n}$ & $\%$ \\
\hline 1 & $\begin{array}{l}\text { I use open-ended questions for } \\
\text { formative assessment in } \\
\text { mathematics classes }\end{array}$ & 0 & 0 & 6 & 8.5 & 18 & 25.4 & 34 & 47.9 & 12 & 16.9 & 5 & 9.8 & 14 & 27.5 & 21 & 41.2 & 10 & 19.6 & 1 & 2.0 \\
\hline 2 & $\begin{array}{l}\text { I create myself mathematics } \\
\text { questions for formative assessment }\end{array}$ & 1 & 1.4 & 8 & 11.3 & 25 & 35.2 & 26 & 36.6 & 9 & 12.7 & 2 & 3.9 & 9 & 17.6 & 19 & 37.3 & 13 & 25.5 & 8 & 15.7 \\
\hline 3 & $\begin{array}{l}\text { I conduct formative assessment in } \\
\text { mathematics classes to identify any } \\
\text { problem that students face }\end{array}$ & 1 & 1.4 & 5 & 7.0 & 18 & 25.4 & 33 & 46.5 & 13 & 18.3 & 1 & 2.0 & 4 & 7.8 & 17 & 33.3 & 19 & 37.3 & 10 & 19.6 \\
\hline 4 & $\begin{array}{l}\text { I assess students' mathematics } \\
\text { understanding using various } \\
\text { methods throughout the learning } \\
\text { process in mathematics classes }\end{array}$ & 0 & 0 & 3 & 4.2 & 11 & 15.5 & 34 & 47.9 & 22 & 31.0 & 0 & 0 & 3 & 5.9 & 22 & 43.1 & 16 & 31.4 & 9 & 17.6 \\
\hline 5 & $\begin{array}{l}\text { I ensure questions given are not } \\
\text { biased to a certain group of students }\end{array}$ & 0 & 0 & 1 & 1.4 & 9 & 12.7 & 36 & 50.7 & 24 & 33.8 & 0 & 0 & 0 & 0 & 11 & 21.6 & 25 & 49.0 & 15 & 29.4 \\
\hline 6 & $\begin{array}{l}\text { I assess students through drawing, } \\
\text { concept mapping and writing in } \\
\text { mathematics classes }\end{array}$ & 8 & 11.3 & 5 & 7.0 & 17 & 23.9 & 32 & 45.1 & 7 & 9.9 & 3 & 5.9 & 13 & 25.5 & 20 & 39.2 & 10 & 19.6 & 5 & 9.8 \\
\hline 7 & $\begin{array}{c}\text { Students' work from formative } \\
\text { assessment is used to increase their } \\
\text { learning }\end{array}$ & 1 & 1.4 & 4 & 5.6 & 13 & 18.3 & 36 & 50.7 & 16 & 22.5 & 0 & 0 & 2 & 3.9 & 12 & 23.5 & 25 & 49.0 & 10 & 19.6 \\
\hline 8 & $\begin{array}{l}\text { I give feedback based on their results } \\
\text { in which I can identify their strength } \\
\text { and weaknesses }\end{array}$ & 0 & 0 & 1 & 1.4 & 13 & 18.3 & 39 & 54.9 & 17 & 23.9 & 0 & 0 & 8 & 15.7 & 12 & 23.5 & 24 & 47.1 & 7 & 13.7 \\
\hline 9 & $\begin{array}{l}\text { I improve my teaching strategy } \\
\text { based on students' feedback }\end{array}$ & 1 & 1.4 & 2 & 2.8 & 9 & 12.7 & 36 & 50.7 & 22 & 31.0 & 0 & 0 & 5 & 9.8 & 12 & 23.5 & 25 & 49.0 & 9 & 17.6 \\
\hline 10 & $\begin{array}{l}\text { I prefer to use subjective questions } \\
\text { compared to multiple-choices } \\
\text { questions in mathematics tests }\end{array}$ & 0 & 0 & 2 & 2.8 & 13 & 18.3 & 32 & 45.1 & 24 & 33.8 & 3 & 5.9 & 5 & 9.8 & 17 & 33.3 & 14 & 27.5 & 12 & 23.5 \\
\hline 11 & $\begin{array}{l}\text { I identify students' mathematics } \\
\text { misconceptions through formative } \\
\text { assessment }\end{array}$ & 0 & 0 & 5 & 7.0 & 19 & 26.8 & 36 & 50.7 & 11 & 15.5 & 0 & 0 & 3 & 5.9 & 9 & 17.6 & 22 & 43.1 & 17 & 33.3 \\
\hline 12 & $\begin{array}{l}\text { I assess students' presentations in } \\
\text { front of the class }\end{array}$ & 0 & 0 & 5 & 7.0 & 20 & 28.2 & 30 & 42.3 & 16 & 22.5 & 1 & 2.0 & 5 & 9.8 & 11 & 21.6 & 21 & 41.2 & 13 & 25.5 \\
\hline
\end{tabular}


As shown in Table 5, for Item 5, 78.4\% of the South Korean respondents answered "often" or "always". In the latest curriculum, students' ability in mathematics is greatly emphasised. According to [43], teachers are able to see students' achievement when they provide questions for formative assessment and students check the answers given through power point presentation. According to [50], at primary schools, after a mathematics concept is introduced, unit assessment is given with the intention of assessing whether students understand the concept from the unit or not. As an outcome from this assessment, teachers give the students either "Let's Study Again" or "Let's Study More" worksheet. The "Let's Study Again" worksheet is given to students with lower achievements, while the "Let's Study More" worksheet is given to students with higher achievements who need higher thinking and more complex applications. Besides, for Item $12,66.7 \%$ of the South Korean respondents answered either "often" or "always". Ref [43] found that some of the normal activities in mathematics classes are group discussions and students' presentations.

The second type of assessment is summative assessment which refers to the assessment conducted after the entire learning unit or after all of the subjects are completed. Year-end examinations and public examinations are included in summative assessment. This assessment is given with the purpose of knowing whether the students have mastered the learning standard required in a curriculum. As shown in Table 6, the Malaysian mathematics teachers emphasised highly on examinations, especially public examinations. It can be seen in Item 1 in which $88.8 \%$ of the respondents chose "often" or "always". When asked about final examinations or public examinations, the two teachers interviewed stated as follows:

"That is... hahaha... our culture. Whether we like it or not, we have to emphasise on final examinations and public examinations. Most of the time, parents themselves will look at their children's results. That is what parents look at. Parents are our clients. We try our best for their children. Our school is highly committed in loving our students. That is our practice". [TM1: H2] "I emphasise a lot on examinations. To me, final examinations and public examinations are significant these days. Students are competing. For example, if we want to enter an institution, we must excel in examinations. There are only a few students who will be qualified to enter any institution". [TM2: H2].

Malaysia is one of the countries that are exam-oriented [51]. This education approach is normal in schools in Asia, which can limit students' creativity [52]. According to [53], Malaysia is very education-oriented. The schools' performance is assessed based on their achievement in public examinations. The teachers' effort is focused on preparing their students for public examinations. Thus, attempts to make a creative lesson using technology are hindered by the continuous requirement for teacher-focused learning with the purpose of finishing the syllabus and preparing students for examinations. One of the Malaysian mathematics teachers interviewed stated:

"Yes. I always emphasise on final examinations and general examinations results to students. We have targets for our school and we chase those targets. If we do not achieve the targets, the administration will be pressured. Administration pressure always exists". [TM3: H2]

To reduce the education system which is too exam-oriented, the Malaysian government has implemented an open certificate examination system at the higher secondary level. In this system, students are allowed to choose various elective subjects other than six core academic subjects, including vocational elective subjects, based on their passion and academic ability [54]. Besides, in 2004, 22 subjects covering production, construction, agriculture technology and computer application are included in the higher secondary school curriculum [55]. These elective subjects are offered for students with poor academic achievements. Nevertheless, [55] has some constraints in terms of teaching staff [56].

As shown in the quantitative data, the teachers implement assessment based on the curriculum requirement; they develop mathematics questions based on the learning objectives of a mathematics topic. It can be seen in Items 6,7 and $8,84.5 \%, 83.1 \%$ and $80.2 \%$ of the respondents answered either "often" or "always". In Malaysia, there is a specific procedure that must be followed by teachers in developing tests for summative assessment. One of them is that the teachers must first develop a test specification table before mathematics questions are developed. These developed questions must represent questions in the form of high and low levels of thinking. In the Malaysian education system, the thinking skills refer to the Revised Bloom's Taxonomy [34], [57]. Lower-Order Thinking Skills (LOTS) refer to the two lowest levels which are remembering and understanding, while Higher-Order Thinking Skills (HOTS) refer to the four highest levels which hare applying, analysing, evaluating and creating. The mathematics questions developed based on JSU along with scoring rubric are given to the head of panel of mathematics for the purpose of checking and verifying.

From the quantitative data, it can be seen that most of the teachers followed the procedures prepared by the Malaysian Examination Syndicate (MES). It can be observed that $77.4 \%$ of the teachers answered "often" or "always" for Item 9, 90.1\% answered the same scale for Item 10, 60.5\% for Item 11, 70.4\% for Item 12 and $90.1 \%$ for Item 13. One of the teachers explained:

"I build some of the items for final exam papers. But they are less than $10 \%$. Some of the items are already provided and validated by Pejabat Pendidikan Daerah. The items have to be prepared teachers. Usually, we 
prepare the questions based on the collection of questions. But, sometimes, we do not take them $100 \%$. We modify or change them. Like form-one teachers, they discuss among themselves. Usually, if we want to send exam questions, we have to get validation from the head of committee or the head of subject. Teachers will discuss it at that time. If the head says that the question is not good, the teachers will try to change the question. Usually, the teachers will answer the questions themselves first. Then, we will see where the weakness is, and we discuss with fellow teachers". [TM1: H2]

This finding shows that the assessment in Malaysia is based on examinations. According to [58], the education system in Malaysia is "top-down" and exam-oriented. It can cause students to focus on examinations only. Although the school-based assessment (SBA) has been implemented to reduce the dependence on examinations, [59] claims that teachers are concerned about the SBA implementation. They are worried about their ability and their role in the SBA implementation. Some of the obstacles include inadequate guidelines for teachers regarding the SBA implementation, lack of teachers' basic knowledge, and lack of monitoring [60].

For Item 15, which is $77.4 \%$ of the respondents stated "often" or "always". This finding is parallel with [60] who assert that teachers are too dependent on reference books and questions prepared by the State Education Department. The excerpt from the interview below further explained about this item:

"I adapt from other sources. I mean, I look at the questions and manipulate them a little bit". [TM2: H2]

"Usually, I adapt from other sources or develop my own questions. I change in between. The current questions are not the same as past questions. We did a little change". [TM3: H2]

As seen in Table 6, for Item 3 which is "I consider the knowledge, skills and values intended into the curriculum while conducting assessment", 73.3\% of the Malaysian respondents answered "often" or "always". This finding shows that the Malaysian teachers assessed not only knowledge, but also skills and values. Nevertheless, based on the interviews with their teachers, only the cognitive domain was assessed formally either through tests or examinations. The psychomotor and affective domains were only assessed informally. Some of the feedbacks are stated below:

"I do not have other tools to evaluate other attributes. I don't know because my school is not as successful as other schools. Although the students in my school are weak, they do not show negative attitudes towards mathematics. They are still doing the exercises. But, they are a few, mostly boys, who could not do the exercises. They are the ones whom the teachers try to approach. They seem to like mathematics, but we do not know if they understand the lessons. Their negative attitude is not so obvious. It is not an issue". [TM1: H2] "I evaluate students based on their confidence to answer questions. But, I do not have a particular instrument to measure. I also look at students' values towards mathematics. But again, I do not have particular tools to evaluate. I only use observation". [TM3: H2]

This finding is parallel with [61] who assert that teachers usually consider students' academic achievement in a way that is more constructive and holistic. The affective aspect, such as value, is overlooked. It does not comply with the four effective characteristics for holistic SBA as specified by the Malaysian Examination Syndicate (LPM) which are (1) displaying the real picture of students' development in learning, (2) implementing teaching and learning in the classroom, (3) showing flexibility in assessment based on specific suitability and readiness, and (4) assessing specific achievement or ability.

This result shows that SBA in Malaysia has not reached a satisfactory level yet. Many teachers focus on the cognitive aspect only, which contradicts the aims of SBA that include academic and non-academic fields across three domains which are cognitive, affective and psychomotor. Besides, SBA aims to assess the learning process and product formatively and summatively by practising assessment for learning (formative summative) and assessment of learning (summative assessment). This finding also shows that the Malaysian teachers are focusing on public examination format such as TIMSS or PISA, although not all schools are going to be chosen randomly in both assessments. It can be seen in Items 4 and 5 in which only $28.2 \%$ and $25.4 \%$ of the respondents answered "often" or "always". The mathematics teachers in South Korea also emphasise on public examinations. When asked about this matter, they said:

"I am trying to reduce the reflection rate of the final exam as much as possible. I emphasise the process of modifying and refining one's own reasoning through observational assessment and feedback". [TK1: H2]

"I will explain the weight of each area in the overall assessment from the beginning of the semester. So, every time I come to each exam, I emphasise the importance of this. I organise my tests mainly on problems that have been dealt with during the lessons or the questions that have arisen among students". [TK3: $\mathrm{H} 2]$

Nevertheless, the quantitative finding shows that only $39.3 \%$ of the South Korean respondents chose "often" or "always" for the first item, although in reality, parents and students highly emphasise on examinations. According to [62], one of the main factors that influence students' mathematics achievement in South Korea is the desire to study and students' hard work. This phenomenon is well known by many people. The focus of primary and secondary education in South Korea is on the subjects 
needed in the national college entrance examination (also known as College Scholastic Ability Test, CSAT). CSAT is a very competitive examination that filters secondary school students before entering a university. Mathematics is one of the four fields assessed in CSAT.

According to [43], summative assessment in South Korea is usually implemented four times a year. As shown in Table $6,74.5 \%, 58.8 \%$ and $74.5 \%$ of the South Korean respondents answered "often" or "always" for Items 6, 7 and 8. It shows that the South Korean teachers implemented summative assessment as required by the mathematics curriculum. The summative assessment implemented at the school level determines the entrance to the higher secondary level. According to [63], South Korean citizens who follow Confucianism have high respect for education since the early century. Confucian philosophy has entered Korea from China for more than the last fifteen centuries [64]. Traditionally Confucianism prepares the exact way for students, which involves a continuous self-cultivation through education. Confucianism, as national ideology and religion, highly influences the politics, economy, society, culture and education in South Korea. By using the Confucian ideas, a merit individual is chosen through regional and national examinations that are very competitive. The examination system acts as the main selection mechanism for the limited government position. Formal education, thus, becomes a preparation for examinations. In addition, according to [63], South Korea has experienced a boom in economy following the success of the national economic development plan. The educational fever (passion), which is based on Confucian social values, has caused the education system to become more exam-oriented. To achieve an excellent result in examinations, $2.9 \%$ of the Korean GDP is spent on related private education as a preparation for examinations for university entrance [65].

The mathematics teachers in South Korea do not prioritise the national assessments such as TIMSS and PISA. It can be seen in Table 6, for Item 2, $100 \%$ of the South Korean respondents answered "never", "seldom" or "sometimes". The mathematics questions also do not follow the format of the two international assessments. For Items 4 and 5, 96.1\% and 94.2\% of the South Korean respondents answered "never", "seldom" and "sometimes". According to [62], students' achievement in the test is influenced by their attitude. South Korean students are raised in a Confucian culture and taught to take the tests seriously. Their attitude towards the TIMSS and PISA assessments might be influenced by their seriousness towards the tests. Besides that, many people claim that South Korean students obtain excellent results in international assessments because they are taught procedurally. According to [66], procedural instruction is not merely asking students to answer "yes" or "no". On the other hand, the learning process begins by strengthening the students' competency in the procedure, and then, through a variety of exercises and systematic implementation, the students gradually acquire a deep understanding. Such scenarios occur among students in East Asian countries. Summative assessment is implemented very systematically in South Korea, as evident in the excerpts below:

"In the case of formative evaluation, I verify through the teacher community, and in the case of general evaluation, I cross-check with the peer teacher in the same school". [TK1: H2]

"I verify it in the way my fellow teachers solve questions". [TK2: H2]

"I exchange ideas with fellow teachers and examine them again after a while". [TK3: H2]

The finding of the interview is parallel with the quantitative finding in this study. As seen in Table 6, $68.6 \%, 56.9 \%, 70.6 \%$ and $86.3 \%$ of the South Korean respondents answered "often" or "always" for Items 10 , 11, 14 and 16. According to [43], for summative assessment, mathematics teachers in South Korea hold a subject community discussion in which all of the mathematics teachers are involved. The discussion covers the setting of assessment, the domain and assessment objective, the assessment framework, the developed test, the grading process, and the report of the outcome. 
Table 6. Construct H2: Summative assessment

\begin{tabular}{|c|c|c|c|c|c|c|c|c|c|c|c|c|c|c|c|c|c|c|c|c|c|}
\hline & \multirow{3}{*}{ Item } & \multicolumn{10}{|c|}{ Malaysia } & \multicolumn{10}{|c|}{ South Korea } \\
\hline & & \multicolumn{2}{|c|}{ Never } & \multicolumn{2}{|c|}{ Seldom } & \multicolumn{2}{|c|}{ Sometimes } & \multicolumn{2}{|c|}{ Often } & \multicolumn{2}{|c|}{ Always } & \multicolumn{2}{|c|}{ Never } & \multicolumn{2}{|c|}{ Seldom } & \multicolumn{2}{|c|}{ Sometimes } & \multicolumn{2}{|c|}{ Often } & \multicolumn{2}{|c|}{ Always } \\
\hline & & $\mathrm{n}$ & $\%$ & $\mathrm{n}$ & $\%$ & $\mathrm{n}$ & $\%$ & $\mathrm{n}$ & $\%$ & $\mathrm{n}$ & $\%$ & $\mathrm{n}$ & $\%$ & $\mathrm{n}$ & $\%$ & $\mathrm{n}$ & $\%$ & $\mathrm{n}$ & $\%$ & $\mathrm{n}$ & $\%$ \\
\hline 1 & $\begin{array}{c}\text { I highlight the } \\
\text { importance of public } \\
\text { examination to students }\end{array}$ & 0 & 0 & 0 & 0 & 8 & 11.3 & 30 & 42.3 & 33 & 46.5 & 4 & 7.8 & 8 & 15.7 & 19 & 37.3 & 14 & 27.5 & 6 & 11.8 \\
\hline 2 & $\begin{array}{c}\text { I highlight the } \\
\text { importance of } \\
\text { international } \\
\text { assessments such as } \\
\text { TIMSS and PISA to } \\
\text { students } \\
\end{array}$ & 2 & 2.8 & 7 & 9.9 & 41 & 57.7 & 13 & 18.3 & 8 & 11.3 & 32 & 62.7 & 14 & 27.5 & 5 & 9.8 & 0 & 0 & 0 & 0 \\
\hline 3 & $\begin{array}{l}\text { I consider the } \\
\text { knowledge, skills and } \\
\text { values intended into the } \\
\text { curriculum while } \\
\text { conducting assessments }\end{array}$ & 0 & 0 & 1 & 1.4 & 18 & 25.4 & 32 & 45.1 & 20 & 28.2 & 4 & 7.8 & 3 & 5.9 & 14 & 27.5 & 18 & 35.3 & 12 & 23.5 \\
\hline 4 & $\begin{array}{c}\text { I give students } \\
\text { mathematics questions } \\
\text { resemble to the ones in } \\
\text { TIMSS } \\
\end{array}$ & 1 & 1.4 & 11 & 15.5 & 39 & 54.9 & 14 & 19.7 & 6 & 8.5 & 31 & 60.8 & 15 & 29.4 & 3 & 5.9 & 1 & 2.0 & 0 & 0 \\
\hline 5 & $\begin{array}{c}\text { I give students } \\
\text { mathematics questions } \\
\text { resemble to the ones in } \\
\text { PISA } \\
\end{array}$ & 2 & 2.8 & 11 & 15.5 & 40 & 56.3 & 12 & 16.9 & 6 & 8.5 & 31 & 60.8 & 14 & 27.5 & 3 & 5.9 & 2 & 3.9 & 0 & 0 \\
\hline 6 & $\begin{array}{l}\text { Assessment is conducted } \\
\text { in line with the intended } \\
\text { teaching and curriculum }\end{array}$ & 0 & 0 & 1 & 1.4 & 10 & 14.1 & 29 & 40.8 & 31 & 43.7 & 0 & 0 & 3 & 5.9 & 10 & 19.6 & 22 & 43.1 & 16 & 31.4 \\
\hline 7 & $\begin{array}{l}\text { I develop mathematics } \\
\text { questions that are in line } \\
\text { with the objective of a } \\
\text { mathematics topic }\end{array}$ & 0 & 0 & 4 & 5.6 & 8 & 11.3 & 32 & 45.1 & 27 & 38.0 & 5 & 9.8 & 5 & 9.8 & 11 & 21.6 & 21 & 41.2 & 9 & 17.6 \\
\hline 8 & $\begin{array}{l}\text { I use assessment that is } \\
\text { in line with national } \\
\text { standards }\end{array}$ & 0 & 0 & 2 & 2.8 & 12 & 16.9 & 28 & 39.4 & 29 & 40.8 & 2 & 3.9 & 2 & 3.9 & 9 & 17.6 & 21 & 41.2 & 17 & 33.3 \\
\hline 9 & $\begin{array}{l}\text { I use questions that can } \\
\text { measure all levels in the } \\
\text { Bloom's Taxonomy }\end{array}$ & 0 & 0 & 2 & 2.8 & 14 & 19.7 & 40 & 56.3 & 15 & 21.1 & 4 & 7.8 & 12 & 23.5 & 21 & 41.2 & 8 & 15.7 & 6 & 11.8 \\
\hline 10 & $\begin{array}{c}\text { I use questions suitable } \\
\text { to students' thinking } \\
\text { level }\end{array}$ & 0 & 0 & 2 & 2.8 & 5 & 7.0 & 41 & 57.7 & 23 & 32.4 & 0 & 0 & 2 & 3.9 & 14 & 27.5 & 22 & 43.1 & 13 & 25.5 \\
\hline
\end{tabular}


Table 6 Continued

\begin{tabular}{|c|c|c|c|c|c|c|c|c|c|c|c|c|c|c|c|c|c|c|c|c|c|}
\hline 11 & $\begin{array}{l}\text { I develop my own } \\
\text { marking rubric }\end{array}$ & 1 & 1.4 & 2 & 2.8 & 25 & 35.2 & 28 & 39.4 & 15 & 21.1 & 2 & 3.9 & 5 & 9.8 & 15 & 29.4 & 19 & 37.3 & 10 & 19.6 \\
\hline 12 & $\begin{array}{l}\text { I use test specification } \\
\text { tables to develop } \\
\text { questions for assessment }\end{array}$ & 0 & 0 & 2 & 2.8 & 19 & 26.8 & 29 & 40.8 & 21 & 29.6 & 4 & 7.8 & 9 & 17.6 & 19 & 37.3 & 11 & 21.6 & 8 & 15.7 \\
\hline 13 & $\begin{array}{l}\text { The mathematics } \\
\text { questions that I develop } \\
\text { are given to the head of } \\
\text { subject/head of } \\
\text { committee to be verified }\end{array}$ & 0 & 0 & 1 & 1.4 & 6 & 8.5 & 23 & 32.4 & 41 & 57.7 & 16 & 31.4 & 9 & 17.6 & 9 & 17.6 & 5 & 9.8 & 12 & 23.5 \\
\hline 14 & $\begin{array}{c}\text { My rubric and answer } \\
\text { scheme are validated } \\
\text { before conducting } \\
\text { assessment }\end{array}$ & 0 & 0 & 5 & 7.0 & 14 & 19.7 & 22 & 31.0 & 28 & 39.4 & 0 & 0 & 2 & 3.9 & 13 & 25.5 & 17 & 33.3 & 19 & 37.3 \\
\hline 15 & $\begin{array}{l}\text { I take mathematics } \\
\text { questions from practice } \\
\text { books and textbooks }\end{array}$ & 0 & 0 & 4 & 5.6 & 12 & 16.9 & 27 & 38.0 & 28 & 39.4 & 0 & 0 & 6 & 11.8 & 18 & 35.3 & 15 & 29.4 & 11 & 21.6 \\
\hline 16 & $\begin{array}{l}\text { I ensure mathematics } \\
\text { questions given are not } \\
\text { repeated from previous } \\
\text { examinations } \\
\end{array}$ & 0 & 0 & 0 & 0 & 16 & 22.5 & 28 & 39.4 & 27 & 38.0 & 1 & 2.0 & 0 & 0 & 5 & 9.8 & 18 & 35.3 & 26 & 51.0 \\
\hline
\end{tabular}


The third type of assessment is diagnostic assessment. Diagnostic assessment in education refers to a form of assessment that occurs before teaching. The purpose of implementing a diagnostic test is to identify students' prior knowledge about a concept before it is taught. It is also implemented to compare students with a certain norm or criterion, to focus on potential weaknesses in individual learning, and to identify gaps among students. As shown in Table 7, the Malaysian mathematics teachers implemented diagnostic assessment in order to identify students' prior knowledge, to understand the students, to examine the effectiveness of teaching tools in mathematics classes, and to explore students' potential. $77.5 \%, 86.0 \%, 87.4 \%$, $59.1 \%, 64.8 \%$ and $60.6 \%$ of the respondents answered either "often" or "always" for Items 1, 2, 3, 9, 10 and 11.

According to [67], one way to collect the information about students' basic skills in mathematics is through a diagnostic test. A diagnostic test in education is an initial assessment that is used especially to detect the strength and weakness of students in learning. It enables educators to fulfil their teaching style and to determine whether their teaching contents are suitable to students' basic knowledge. Many studies have shown the effectiveness of diagnostic assessment towards students' academic achievements. Ref [67] claim that there is a strong positive correlation between mathematics diagnostic test results and students' mathematics achievements. Ref [68] found that diagnostic assessment can be used to fix students' misconception. By integrating cognitive psychology principles with the feedback analysis, diagnostic assessment can identify the mistakes that often interrupt students' learning towards a certain mathematics concept. Ref [69] assert that students face a different difficulty level when they learn the Time involving dates topic. Diagnostic assessment can provide detailed information about students' strength and weaknesses in certain concepts of the Time involving dates topic. This information can provide various feedbacks that can be used for multiple purposes by mathematics teachers and students.

As indicated in Table 7, the Malaysian respondents used the information from diagnostic tests to hold remedial classes for students, to increase teaching quality, and to change the teaching method based on students' learning. $39.4 \%, 45.1 \%, 45.1 \%, 42.3 \%$ and $45.0 \%$ of the respondents answered either "often" or "always" for Items 4, 5, 6, 7 and 8. According to [70], one of the teachers' main challenges is the diagnosis of learning process and students' thoughts. For this purpose, teachers must search for relevant information from a diagnostic test. The interviews with two teachers show that they implemented diagnostic assessment and used the information to change their teaching method. The related excerpt is as follows:

"For example, the students got certain marks. Some got high marks, and some got low marks. We modify our lesson plan accordingly. For example, if students consume time to understand a middle concept, we modify our method. Usually, we only modify the method". [TM3: H3]

One teacher asserted that she did not implement a diagnostic test on all students. Instead, she only identified weaker students. She also conducted a mentor-mentee session and monitored the students' progress. The related excerpt is as follows:

"Usually, for diagnostics, we do not do it to all students. We do diagnostics tests for weak students. That is all. I identify weak students first. We do mentor-mentee. I mean, for mentees, we first search for topics that we will emphasise. Usually, the topics involve lower-levels. This is because, sometimes, weak students could not do lower-level questions. We emphasise more on that. So, for diagnostics tests $1,2,3,4$, teachers look at the students' development. We look at the percentage. Teachers have to ensure that the diagnostics test percentage is above the target. I mean, the tests are by chapters. The percentage must be above $60 \%$. Students must achieve that. If not, the students must repeat". [TM1: H3]

A diagnostic test is usually conducted before teaching. When asked whether teachers conduct a pre-test before teaching, the Malaysian teachers said:

"Pre-test? Hahaha. Pre-test is not our practice. If we want to do action research, then we will do a pre-test". [TM1: H3]

"No. I do not use a pre-test before teaching in my mathematics class". [TM3: H3]

The South Korean mathematics teachers, however, answered the opposite:

'I conduct a pre-test because it is based on the students' discourse and the workbook they have written just after math class. Confirming students' prior knowledge helps to plan ahead of what kind of discussion should be done in the class. No separate pretesting is carried out". [TK1: $\mathrm{H} 3$ ]

"Whenever a unit changes, I simply test the students' prior knowledge to learn the new unit. Through these tests, I identify the shortcomings of students”. [TK2: H3]

The South Korean mathematics teachers were asked about how they used the information from the diagnostic test:

"Students' prior knowledge is important. I can select and plan some major issues to be discussed while leading the class". [TK1: H3]

"I have time to learn some prior knowledge they do not know". [TK2: H3]

"Based on students' lack of understanding of certain concepts, I will give a brief description of these concepts in class". [TK3: H3]

Diagnostic assessment is highly emphasised in the lower secondary education system in South Korea. $70.6 \%, 58.8 \%$, $58.8 \%, 60.8 \%, 56.9 \%, 62.7 \%, 60.8 \%, 62.7 \%, 52.9 \%$ and 
$64.7 \%$ of the South Korean respondents answered "often" or "always" for Items $1,2,3,5,6,7,8,9,10$ and 11. According to [43], diagnostic assessment in South Korea mostly occurs at the start of a mathematics class, which usually takes five to eight minutes. This duration is called "checking prior learning" in which the teachers check on students' prior knowledge. Ref [43] claim that many South Korean teachers conduct diagnostic tests at the start of a class.

In South Korea, diagnostic assessment is highly emphasised. To facilitate teachers to conduct diagnostic assessment systematically, teachers' guidebooks can be used as a complementary for textbooks. The culture of this diagnostic assessment implementation actually exists in the education system in South Korea. Until today, there are two national tests. One of them is Diagnostic Test for Basic Skills (DTBS) for elementary school students [71]. According to $[72,73]$, there are three main objectives of the DTBS implementation. Firstly, DTBS is a basic assessment that provides required information for the country. Secondly, DTBS proves whether a student has already achieved the minimum skills of reading, writing and arithmetic at the Grade 3 level. Thirdly, DTBS provides remedial education programmes to support students who are below the minimum competency level. In the official document about the mathematics curriculum issued by the Ministry of Education South Korea, and in the Guidelines for Teaching and Learning, and Assessment (Methods of Assessments), it is stated that diagnostic assessment must be conducted at different times along the teaching cycle. The various information collected through a continuous assessment must be applied to assess and improve the teaching of mathematics.

The significant difference between Malaysia and South Korea can be found in Items 5, 6, 7 and 8. The percentage of South Korean respondents who answered "often" or "always" is higher than that of Malaysian respondents. $60.8 \%, 56.9 \%, 62.7 \%$ and $60.8 \%$ of the South Korean respondents answered "often" or "always" for Items $5,6,7$, and 8 , while $45.1 \%, 45.1 \%, 42.3 \%$ and $45.0 \%$ of the Malaysian respondents answered "often" or "always" for the same items. Ref [47] states that, in mathematics classes in South Korea, the learning and teaching process is divided into three main parts which are planning, implementation and assessment. The planning phase is divided into the preparation and diagnosis assessment phases. The preparation phase is followed by the diagnosis assessment phase in which the learning objective is reviewed, the assessment information is recollected, and the probability of the teaching direction is reconsidered. The mathematics teachers in South Korea realise the importance of diagnosis before making their teaching plan. 
Table 7. Construct H3: Diagnostic assessment

\begin{tabular}{|c|c|c|c|c|c|c|c|c|c|c|c|c|c|c|c|c|c|c|c|c|c|}
\hline & \multirow{3}{*}{ Item } & \multicolumn{10}{|c|}{ Malaysia } & \multicolumn{10}{|c|}{ South Korea } \\
\hline & & \multicolumn{2}{|c|}{ Never } & \multicolumn{2}{|c|}{ Seldom } & \multicolumn{2}{|c|}{ Sometimes } & \multicolumn{2}{|c|}{ Often } & \multicolumn{2}{|c|}{ Always } & \multicolumn{2}{|c|}{ Never } & \multicolumn{2}{|c|}{ Seldom } & \multicolumn{2}{|c|}{ Sometimes } & \multicolumn{2}{|c|}{ Often } & \multicolumn{2}{|c|}{ Always } \\
\hline & & $\mathrm{n}$ & $\%$ & $\mathrm{n}$ & $\%$ & $\mathrm{n}$ & $\%$ & $\mathrm{n}$ & $\%$ & $\mathrm{n}$ & $\%$ & $\mathrm{n}$ & $\%$ & $\mathrm{n}$ & $\%$ & $\mathrm{n}$ & $\%$ & $\mathrm{n}$ & $\%$ & $\mathrm{n}$ & $\%$ \\
\hline 1 & $\begin{array}{l}\text { I plan assignments and } \\
\text { mathematics questions } \\
\text { related to previous } \\
\text { lessons in order to } \\
\text { identify students' } \\
\text { existing knowledge } \\
\end{array}$ & 0 & 0 & 2 & 2.8 & 14 & 19.7 & 32 & 45.1 & 23 & 32.4 & 0 & 0 & 4 & 7.8 & 10 & 19.6 & 26 & 51.0 & 10 & 19.6 \\
\hline 2 & $\begin{array}{c}\text { I plan mathematics } \\
\text { assignments that can } \\
\text { assess students' existing } \\
\text { knowledge }\end{array}$ & 0 & 0 & 0 & 0 & 10 & 14.1 & 43 & 60.6 & 18 & 25.4 & 0 & 0 & 3 & 5.9 & 17 & 33.3 & 21 & 41.2 & 9 & 17.6 \\
\hline 3 & $\begin{array}{l}\text { The mathematics } \\
\text { questions developed to } \\
\text { enable me to get a better } \\
\text { understanding of my } \\
\text { students }\end{array}$ & 0 & 0 & 1 & 1.4 & 8 & 11.3 & 44 & 62.0 & 18 & 25.4 & 1 & 2.0 & 8 & 15.7 & 11 & 21.6 & 21 & 41.2 & 9 & 17.6 \\
\hline 4 & $\begin{array}{l}\text { I use diagnostic tests to } \\
\text { identify strength and } \\
\text { weaknesses in my } \\
\text { students' knowledge and } \\
\text { skills } \\
\end{array}$ & 4 & 5.6 & 8 & 11.3 & 31 & 43.7 & 23 & 32.4 & 5 & 7.0 & 4 & 7.8 & 7 & 13.7 & 17 & 33.3 & 16 & 31.4 & 7 & 13.7 \\
\hline 5 & $\begin{array}{l}\text { The results of diagnostic } \\
\text { tests help me conduct a } \\
\text { recovery class for } \\
\text { students who are weak in } \\
\text { mathematics }\end{array}$ & 3 & 4.2 & 8 & 11.3 & 27 & 38.0 & 26 & 36.6 & 6 & 8.5 & 2 & 3.9 & 6 & 11.8 & 12 & 23.5 & 20 & 39.2 & 11 & 21.6 \\
\hline 6 & $\begin{array}{l}\text { I plan the next teaching } \\
\text { lesson based on the } \\
\text { information gathered } \\
\text { from a mathematics } \\
\text { diagnostic test }\end{array}$ & 3 & 4.2 & 6 & 8.5 & 29 & 40.8 & 26 & 36.6 & 6 & 8.5 & 3 & 5.9 & 5 & 9.8 & 14 & 27.5 & 18 & 35.3 & 11 & 21.6 \\
\hline 7 & $\begin{array}{l}\text { I use the information } \\
\text { gathered from a } \\
\text { mathematics diagnostic } \\
\text { test to increase my } \\
\text { teaching quality }\end{array}$ & 3 & 4.2 & 8 & 11.3 & 29 & 40.8 & 23 & 32.4 & 7 & 9.9 & 0 & 0 & 7 & 13.7 & 12 & 23.5 & 20 & 39.2 & 12 & 23.5 \\
\hline 8 & $\begin{array}{l}\text { I adjust my teaching } \\
\text { based on the diagnostic } \\
\text { data regarding my } \\
\text { students' learning style }\end{array}$ & 3 & 4.2 & 7 & 9.9 & 28 & 39.4 & 27 & 38.0 & 5 & 7.0 & 1 & 2.0 & 4 & 7.8 & 15 & 29.4 & 20 & 39.2 & 11 & 21.6 \\
\hline
\end{tabular}


Table 7 Continued

\begin{tabular}{|c|c|c|c|c|c|c|c|c|c|c|c|c|c|c|c|c|c|c|c|c|c|}
\hline 9 & $\begin{array}{c}\text { The results of } \\
\text { mathematics diagnostic } \\
\text { tests can give } \\
\text { information regarding } \\
\text { the usage of teaching } \\
\text { aids in mathematics } \\
\text { classes } \\
\end{array}$ & 3 & 4.2 & 8 & 11.3 & 17 & 23.9 & 38 & 53.5 & 4 & 5.6 & 2 & 3.9 & 6 & 11.8 & 11 & 21.6 & 22 & 43.1 & 10 & 19.6 \\
\hline 10 & $\begin{array}{l}\text { I can see my students' } \\
\text { potential from the results } \\
\text { of mathematics } \\
\text { diagnostic tests }\end{array}$ & 3 & 4.2 & 6 & 8.5 & 15 & 21.1 & 38 & 53.5 & 8 & 11.3 & 2 & 3.9 & 7 & 13.7 & 15 & 29.4 & 20 & 39.2 & 7 & 13.7 \\
\hline 11 & $\begin{array}{c}\text { I believe diagnostic } \\
\text { assessment is important } \\
\text { to gather more } \\
\text { information about my } \\
\text { students }\end{array}$ & 2 & 2.8 & 5 & 7.0 & 20 & 28.2 & 32 & 45.1 & 11 & 15.5 & 1 & 2.0 & 4 & 7.8 & 13 & 25.5 & 20 & 39.2 & 13 & 25.5 \\
\hline
\end{tabular}




\section{Conclusions}

From the assessment components studied in this study, the discussion has been divided into three subcomponents, namely formative assessment, summative assessment and diagnostic assessment. For formative assessment, lower secondary school mathematics teachers in both countries have applied it consistently. In line with the goals of South Korea's mathematical curriculum being used today, formative evaluation in mathematical classes focuses not only on cognitive aspects but also on effective aspects. South Korean teachers also use various methods to assess cognitive domains and effective students. On the other hand, lower secondary school mathematics teachers in Malaysia are more likely to assess cognitive aspects such as understanding, problem-solving skills, achievements and so on [74]. Here, we see how the main goal of a curriculum affects education assessment practices in a country. For summative assessments, Malaysia and South Korea are countries with an examination-oriented education system. In South Korea, students are raised on Confucianism that emphasises education. This is coupled with the entrance exams to universities that are very competitive as the education system in South Korea is examination-oriented. In Malaysia, teachers spend on the syllabus in preparing students for the final year examination or public examinations. The achievement of a school is geared towards the achievement of students in public examinations. Teachers may also be questioned over the deterioration of students in the final examination as well as public examinations. In addition, both education systems do not emphasise international assessments such as TIMSS or PISA. This is because in Malaysia, not all schools are chosen to be involved in the assessment. While the attitude of the students towards any tests or exams makes South Korean students ready to face the two assessments. For diagnostic evaluation, its implementation is seen more systematic in South Korea than Malaysia. It is emphasised as early as primary school with guidebooks containing questions that can be used as diagnostics test provided as complementary to the textbook. Even pre-tests are conducted early in the classroom to identify students' existing knowledge before students are taught according to their respective achievement levels. All in all, it can be concluded that Malaysia's and South Korea's assessment practices are similar. The goal of the lower secondary mathematics curriculum greatly influences the practice of assessment in mathematics classes. One of the aspects that Malaysia's education system can learn is the implementation of diagnostic assessments that is highly emphasised in South Korea's education system.

\section{Acknowledgments}

This work is supported by the Korea Foundation for Advanced Studies' International Scholar Exchange
Fellowship for the academic year of 2018-2019.

\section{REFERENCES}

[1] Yang, B. R. \& Mansor, N. (2016). South Korea and Asian: Strategic partnership for building an East Asian community. The dynamics of South Korea's relationship with Asia-Pacific. The KISEAS research series No. 12, Myung in publisher

[2] Uqbah, I. (2016). South Korea's interest in the Malaysian socio-economic development. The history of the Look-To-The-East Idea. National University of Malaysia. Grin. p. 44. ISBN 978-3-6682015-5-2. Retrieved 25 November 2017.

[3] Rasid, A. H. (2018, February 3). South Korean SK group signs MoU with Malaysia. New straits times.

[4] Mills, M. \& McGregor, G. (2016). Learning not borrowing from the Queensland education system: lessons on curricular, pedagogical and assessment reform. The curriculum journal; 27 (1), 113-133, Doi: 10.1080/09585176.2016.1147969

[5] Curriculum, Pedagogy, Assessment \& Reporting T-12. (2018). A framework for quality education in northern territory schools. Northern territory board of studies.

[6] Achtenhagen, F. (2012). The curriculum instruction assessment triad. Empirical research in vocational training; $4(1), 5-25$.

[7] Moeller, A. (2005). Optimising student success: focused curriculum, meaningful assessment, and effective instruction, Year of languages: challenges, changes and choices: selected papers from the 2005 Central States conference, pp. 77.

[8] Bernstein, B. (1975). Class, codes and control volume 3: Towards a theory of educational transmissions. London: Routledge.

[9] Hayward, L., Higgins, S., Livingston, K. \& Wyse, D. (2016). Editorial. The curriculum journal; 27(2), 169-171, Doi: 10.1080/09585176.2016.1179526

[10] Zhao, D. (2016). Review of the literature: Factors contributing to achievement GAP. In: Chinese students' higher achievement in mathematics. Mathematics educationAn Asian perspective. Springer: Singapore

[11] Abdullah, A. H. \& Zakaria, E. (2012). The activities based on van hiele's phase-based learning: Experts' and preservice teachers' views. Journal of Mathematics and Statistics; 8(3), 385-395. Doi: 10.3844/jmssp.2012.385.395

[12] Vey, L. D. (2005). Enhancing the relationship between learning and assessment. $\mathrm{PhD}$ thesis, University of Canberra, Australia.

[13] Kulm, G. (1994). Mathematics assessment: What works in the classroom? San Fransisco, CA: Josey-Bass.

[14] Hussain, A. (2008). Effects of classroom Assessment practices on students' achievement goals. Educational assessment; 13(4), 243-266, Doi: 10.1080/ 10627190802602509

[15] Shihab, J. (2011). The impact of assessment on students 
learning. Procedia-social and behavioral sciences; 28(2011), 718-721.

[16] Shewbridge, C., Hulshof, M., Nusche, D. \& Staehr, L. S. (2014). OECD reviews of evaluation and assessment in education. Northern Ireland, UK. Retrieved from http://dx.doi.org/10.1787/9789264207707-en

[17] Wahab, R.A., Abdullah, A.H., Abu, M.S.B., Bt Mokhtar, M.\& Atan, N.A. (2016). A case study on visual spatial skills and level of geometric thinking in learning 3D geometry among high achievers. Man in India; 96(1-2), 489-499.

[18] Andersson, C. \& Palm, T. (2017). The impact of formative assessment on student achievement: A study of the effects of changes to classroom practice after a comprehensive professional development programme. Learning and instruction; 49, 92-102.

[19] Nusche, D., Laveault, D., MacBeath, J. \& Santiago, P. (2012). OECD Reviews of evaluation and assessment in education: New Zealand 2011, OECD Publishing. http://dx.doi.org/10.1787/9789264116917-en

[20] Davison, C. (2012). Leading in assessment for Learning: Mediating the change. Presented at 4th APS global education conference Singapore, July 2012.

[21] Kennedy, K. J. (2007). Barriers to innovative school practice: A socio-cultural framework for understanding assessment practices in Asia. Paper prepared for the symposium: "student assessment and its social and cultural contexts: How teachers respond to assessment reforms". Redesigning pedagogy - culture, understanding and practice conference, Singapore, 28-30 May 2007.

[22] Kim, B. (2017). The problem of entrance exam-oriented education and its solution plans in Korea. Asia pacific journal of contemporary education and communication technology (APJCECT); 3(1), 283-290.

[23] Saw, L.O. (2010). Assessment profile of Malaysia: highstakes external examinations dominate. Assessment in education: Principles, Policy \& Practice, 17(1), 91-103.

[24] Arnove, R. F., Franz, S. \& Kubow, P. K. (2016). Comparative education. Oxford University Press.

[25] Fraser, S. E. \& Brickman, W. W. (1968). A history of international and comparative education: Nineteenth-century documents. Glenview, IL: Scott, Foresman.

[26] Merriam, S.B. (2002). Introduction to qualitative research. In S. B. Merriam (Ed.), Qualitative research in practice: Examples for discussion and analysis. San Francisco, USA: Jossey Bass.

[27] Arnove, R.F. \& Torres, C.A. (2007). Comparative education: The dialectic of global and local. New York: Rowman \& Littlefield.

[28] Trizano, H., Jesus, M. \& Alvardo, I. (2016). Best alternatives to cronbach's alpha reliability in realistic conditions: congeneric and asymmetrical measurements. Front psychol. 2016; 7: 769. Doi: 10.3389/fpsyg.2016.00769

[29] George, D. \& Mallery, P. (2003). SPSS for windows step-by-step: A simple guide and reference (4th Ed.). Boston: Allyn \& Bacon.
[30] Schwandt, T. A. (2001). Qualitative inquiry: A dictionary of terms (2nd Ed.). Thousand Oaks, CA: Sage.

[31] Schultze, U. \& Avital, M. (2011). Designing interviews to generate rich data for information systems research. Information and Organization; 21, 1-16.

[32] Din, A. G. M. (2003). Prinsip dan amalan pengajaran. Kuala Lumpur: Utusan Publications.

[33] Sardareh, S.A. \& Saad, M.R.M. (2013). Malaysian primary school ESL teachers' questions during assessment for learning. English language teaching; 6(8), 1-9.

[34] Bahagian Pembangunan Kurikulum (BPK). (2017). Dokumen Standard Kurikulum dan Pentaksiran Matematik. Putrajaya: Kementerian Pendidikan Malaysia.

[35] Abdullah, A. H, Ibrahim, N. H., Surif, J., Ali, M. \& Hamzah, M. H. (2014). Non-routine mathematical problems among in-service and pre-service mathematics teachers, 2014 IEEE International Conference on Teaching, Assessment and Learning for Engineering (TALE), Wellington, 2014, pp. 18-24. Doi: 10.1109/TALE.2014.7062620

[36] Chaoui, N. (2011). Finding relationships between multiple-choice math tests and their stem-equivalent constructed responses (Unpublished doctoral dissertation). The Claremont Graduate University, California, USA.

[37] Stankous, N. V. (2016). Constructive response vs multiple-choice tests in math: American experience and discussion (review). European scientific journal; 12(3), 308-316

[38] Berg, M. V. D., Bosker, R. J. \& Suhre, C. J. M. (2018) Testing the effectiveness of classroom formative assessment in Dutch primary mathematics education. School effectiveness and school improvement; 29(3), 339-361.

[39] Ugodulunwa, C.A. \& Okolo, U.P. (2015). Effects of formative assessment on mathematics test anxiety and performance of senior secondary school students in Jos, Nigeria. IOSR journal of research \& method in education (IOSR-JRME); 5(2), 38-47.

[40] Pla-Campasa, G., Arumí-Pratb, J., Senye-Mirc, A.M. \& Ramírez, E. (2016). Effect of using formative assessment techniques on students' grades. Procedia-social and behavioral sciences; 228(2016), 190-195.

[41] Suurtamm, C. \& Neubrand, M. (2015). Assessment and testing in mathematics education. In S.J. Cho (Ed.), the proceedings of the 12th International Congress on Mathematical Education (pp. 557-562). Dordrecht, the Netherlands: Springer.

[42] Klenowski, V. (2009). Assessment for learning revisited: An Asia-pacific perspective. Assessment in education: principles, policy, and practice; 16(3), 263-268.

[43] Han, I. \& Kim, Y. (2013). Assessment in Korean mathematics classroom. In Mogens, N., Lee, P.N., \& Jeremy, K. (Eds.), Mathematics education in Korea: curricular and teaching and learning practices (pp. 253-288). Singapore: world scientific.

[44] Looney, J. W. (2011). Integrating formative and summative assessment: Progress toward a seamless system? OECD education working papers, No. 58, OECD Publishing. http://dx.doi.org/10.1787/5kghx3kbl734-en 
[45] Ministry of Education, Science and Technology (MEST, 2009). The plan for advancing the education service industry. Seoul.

[46] Lee, S. H. (2014). Korean middle- and high-school math teachers' understanding of formative assessment (Unpublished doctoral dissertation). University of Illinois at Urbana-Champaign, USA.

[47] Kim, M. K. \& Cho, M. K. (2015). The study of constructed-response assessment of elementary mathematics education in Korea. Eurasia journal of mathematics, science \& technology education; 11(2), 299-311.

[48] Kim, S. (2015). Master teacher's role in professional development and the mentor teacher system. In J. Kim, I. Han, M. Park \& J. Lee (Eds.). Mathematics education in Korea volume 2: Contemporary trends in researches in Korea (pp. 57-75).

[49] Kang, O. (2000). A theory of teaching and assessment in mathematics. Seoul: Kyungmunsa.

[50] Pang, J. (2013). Current elementary mathematics textbooks. In In J. Kim, I. Han, M. Park \& J. Lee (Eds.). Mathematics education in Korea: Curricular and teaching and learning practices (pp. 43-61). Danvers, U.S: World Scientific Publishing.

[51] Lim, C. S. \& Hwa, T. Y. (2007). Promoting mathematical thinking in the Malaysian classroom: Issues and challenges. Paper presented at the APEC-Tsukuba International Conference: Tsukuba University, Tokyo, Japan, December, pp. 2-7.

[52] Beech, H. (2002, April 15). School daze. Time, 159, 44-51.

[53] Kader, B. K. A. (2008). Malaysia's experience in training teachers to use ICT. In E. Meleisea (Ed.), ICT in teacher education: Case studies from the Asia-Pacific region (pp. 61-66). Bangkok: UNESCO Publication.

[54] Ministry of Education Malaysia. (2001). Education in Malaysia: A journey to excellence. Kuala Lumpur.

[55] Ministry of Education Malaysia. (2006). Ninth Malaysia Plan: National educational development blueprint 2006-2010. Malaysia.

[56] Yao, S. T. (2011). Democratization of secondary education in Malaysia: attitudes towards schooling and educational aspirations. Asia pacific journal of education; 31(1), 1-18, Doi: 10.1080/02188791.2011.544055

[57] Anderson, L. W. \& Krathwohl, D. R. (2001). A Taxonomy for learning, teaching and assessing: A revision of bloom's taxonomy of educational objectives. Complete Edition. New York: Longman.

[58] Balakrishnan, V. (2012). Dilema kehidupan sebenar dalam pendidikan moral. Kuala Lumpur: Penerbit Universiti Malaya.

[59] Majid, F.A. (2011). School-based assessment in Malaysian schools: The concerns of the English teachers. US-China Education Review; B3(2011), 393-402.

[60] Malakolunthua, S. \& Hoon, S. K. (2010). Teacher perspectives of school-based assessment in a secondary school in Kuala Lumpur. Procedia-social and behavioral sciences; 9(2010), 1170-1176.

[61] Veloo, R., Ramli, R. \& Khalid, R. (2016). Assessment practices among English teachers in Malaysian secondary schools. International journal for infonomics (IJI); 9(4), 1220-1227.

[62] Park, K. (2004). Factors contributing to Korean students' Hugh achievement in mathematics. The report on mathematics education by Korea sub-commission of ICMI (KSICMI). The Korean presentation at ICME-10, Copenhagen, Denmark, July 6, pp.85-92.

[63] Lee, J. K. (2006). Educational fever and South Korean higher education. REDIE; 8(1), 1-14.

[64] Kwon, S. K., Lee, M. \& Shin, D. (2015). Educational assessment in the Republic of Korea: Lights and shadows of high-stake exam-based education system. Assessment in education: Principles, policy \& practice; 24(1), 60-77.

[65] Dawson, W. (2010). Private tutoring and mass schooling in East Asia: Reflections of inequality in Japan, South Korea, and Cambodia. Asia pacific education review, 11, 14-24.

[66] Leung, F. K. (2001). In search of East Asian identity in mathematics education. Educational studies in mathematics; $47(1), 35-51$

[67] Shim, G. T. G., Shakawi, A. M. H. A. \& Azizan, F. L. (2017). Relationship between students' diagnostic assessment and achievement in a pre-university mathematics course. Journal of education and learning; 6(4), 364-371.

[68] Ketterlin-Geller, L. R. \& Yovanoff, P. (2009). Diagnostic assessments in mathematics to support instructional decision making. Practical assessment, research \& evaluation; 14(16), $1-11$.

[69] Ling, T. P., Sam, L. C. \& Kee, K. L. (2017). Diagnosing primary pupils' learning of the concept of after in the topic time through knowledge states by using cognitive diagnostic assessment. Malaysian journal of learning and instruction; $14(2), 145-175$.

[70] Hoth, J., Döhrmann, M., Kaiser, G., Busse, A., König, J. \& Blömeke, S. (2016). Diagnostic competence of primary school mathematics teachers during classroom situations. ZDM mathematics education; 48(2016), 41-53.

[71] Park, H. (2008). Korean perspectives on assessment of student achievement. Educational studies in Japan: International Yearbook, No.3, December, 2008, pp.17-25.

[72] Chae et al. (2003). Information security application. The 4th workshop on information security applications (WISA 2003), Jeju Island, Korea, August 25-27, 2003. Revised papers.

[73] Abdullah, A. H., Rahman, S. N. S. A. \& Hamzah, M. H (2017). Metacognitive skills of Malaysian students in non-routine mathematical problem solving. Bolema: Mathematics Education Bulletin; 31(57), 310-322.

[74] Muhammad, S. A., Abdullah, A. H., Shamsuddin, N. S., Abd Rahman, S. N. S., Ashari, Z. M., Jumaat, N. F., Abu-Samah, N. \& Ali, D. F. (2020). Pupil's behaviour pattern and non-routine mathematical problem-solving strategy based on multiple intelligences. JARDCS; 12(3), 466-485. Doi: 10.5373/JARDCS/V12I3/20201214 